\title{
What Accounting Students Consider Important In The Job Selection Process
}

Mr. Paul Bundy, Staff Auditor, Deloitte \& Touche

Dr. Daniel Norris, Accounting, Iowa State University

\begin{abstract}
The purpose of this study is to determine what factors accounting students consider important in the selection of their first job. These preferences are identified and analyzed with respect to individual characteristics such as gender, age, career aspirations, and work experiences. In addition, the effects of the job interviewing process on students' perceptions of the relative importance of the various job attributes is examined.
\end{abstract}

\section{Introduction}

One of the most difficult challenges facing the accounting profession is the recruitment and retention of highquality personnel. Competition for the "best and the brightest" accounting graduates is intense, particularly among large public accounting firms, which experience high turnover rates as talented employees leave for more lucrative and less stressful positions in private industry. To properly give advice to accounting students and to campus recruiters, departmental administrators and academic advisors must thoroughly understand the factors that accounting students consider in choosing their first jobs.

The purpose of this study is to review the related literature and conduct a research project that combines many of the job selection preferences used in previous studies. These preferences are identified and analyzed with respect to individual characteristics such as gender, age, and career aspirations. The study also attempts to determine the impact of the above individual characteristics on the likelihood that an accounting student will be chosen for one or more on-campus interviews and that such interviews will lead to office visits and/or job offers. Finally, how the on-campus interviewing process influences students' perceptions about their future accounting careers is examined.

\section{Previous Research}

Much research has been conducted on the job selection preferences of accounting students, some of which has produced results which may at first seem surprising. Several studies, for instance, have shown that, while accounting traditionally has been a high-paying profession, accounting students generally do not view salary as the most important consideration in choosing their first jobs. Carpenter and Strawser (1970) asked a group of undergraduate accounting students to rank 11 job characteristics.

The respondents ranked starting salary as the third most important criterion, following nature of work and opportunities for advancement. Working conditions and job security were the fourth- and fifth-ranked criteria, respectively.

Director and Doctors (1973) asked placement directors at graduate business schools what factors students look for when evaluating prospective jobs. The respondents, choosing from a list of eight job selection criteria, ranked interesting work and potential for advancement first and second in order of importance, followed by salary, location and prestige. Pensions was ranked as the least important criterion by the placement directors surveyed.

Catalanello, Wegener and Zikmund (1978), in a survey of MBA students, found that salary acts as a negative, rather than a positive, influence on job selection. The researchers asked the MBA's to estimate the chances of their accepting hypothetical job offers. The responses suggested that MBA's tend to establish a lower salary limit below which they will not go; however, a salary offer above the threshold has little additional influence on a student's decision to accept or reject a job.

A large body of research indicates that gender has a significant influence on the job selection process. Kochanek and Norgaard (1985a,b) asked a group of accounting students who had accepted a job or who had an offer they planned to accept to rank the factors which had most significantly influenced their decision. Women ranked as most important firm personnel, followed by firm location and opportunities for advancement. Men also ranked firm personnel as the most important criterion, but reversed the rankings for the other two factors.

Reed and Kratchman (1989) distributed a list of 35 job attributes to a sample of senior accounting majors. The subjects were asked to rate the importance of these attributes. The researchers concluded that women were more interested than men were in jobs which permit personal growth and require little travel or overtime, while men preferred jobs that allow them to exercise leadership 
qualities and use originality.

In a similar study, Lathan, et al (1987) asked graduating accounting majors to rank 12 quantitatively selected attributes of potential employers. The researchers identified promotion opportunities and prospects for high future earnings as factors more important to male job seekers. The same study found that females were more interested in warm, friendly personnel, continuing professional development, location, fringe benefits, starting salary, and amount of travel and overtime required.

Manhardt (1972) provides a possible explanation for the gender-related differences found in the above studies. After analyzing data from a five-year study of college graduates, he found that men rated characteristics contained in an advancement/responsibility factor higher than did women, while women gave higher ratings to characteristics contained in a work environment factor. Manhardt concluded that a significant proportion of women do not regard a job and a career as a significant factor in their lives and thus are more concerned with job selection factors relating to work environment than to long-term career success.

Other studies have explored the relationship between individual characteristics such as gender, marital status, and grade point average and the career choices of accounting students. Shivaswamy and Hanks (1986) conducted a survey of accounting students and found that the males in the sample expressed more of an interest in public accounting and less of an interest in not-for-profit accounting than did the females. The researchers found that students with higher GPAs and students closest to graduation ranked public accounting ahead of industrial/commercial accounting, while students with lower GPAs and those furthest from the job market reversed the rankings. The differences in the mean scores of married and single students were not statistically significant.

Although much has been written about the job selection preferences of accounting students, most existing studies have ignored the impact of the job interviewing process on the development of such perceptions. One recent study provides some evidence that participation in job interviews does little to shape student attitudes towards potential employers. Schmutte (1987a,b) surveyed 86 accounting seniors both before and after the fall recruiting period at Ball State University to find out how much importance the students assigned to 54 employer characteristics when selecting a public accounting firm as an employer. Schmutte found that only three of the characteristics studied-the size of the office's professional staff, the office's relaxed atmosphere, and the male/female ratio of the firm's professional staff-increased significantly in perceived importance after the interviewing process, while none of the characteristics decreased significantly in importance.

Another unique aspect of the Schmutte study is that the researcher examined the impact of age on job selection criteria. Schmutte found that students 23 years old or older were more concerned about a relaxed office atmosphere and friendly staff members and were less concerned about the firm's on-campus reputation than were younger students.

\section{Methodology}

The subjects for this study all were students enrolled in upper-level accounting courses at Iowa State University. The instructors of these courses agreed to distribute a questionnaire, together with an explanatory cover letter, to their students. Written instructions for distribution were provided to each instructor. Students were asked to complete and return the questionnaires on their own. A 50dollar cash drawing was announced and conducted as an incentive for students to return the questionnaires. To prevent duplicate responses, the subjects were asked to print their names on the final page of the survey. To ensure confidentiality, the subjects were assured that the final page would be detached before the data was analyzed.

A total of 253 questionnaires were distributed, of which $172(68 \%)$ were returned. Although some returned questionnaires contained incompleted questions, the percentage of such questions was not high enough to render any of the returned questionnaires unusable. Of the total respondents, equal numbers were male and female. In terms of educational level, $31.4 \%$ were juniors, $64.0 \%$ were seniors, and only $4.6 \%$ were graduate students. A more complete list of subject demographics is presented in Table 1.

The subjects were asked first to provide specified demographic information, then to indicate their perceptions about the relative importance of 35 selected job attributes. The job attributes were acquired in part from studies conducted by Reed and Kratchman (1989), Schmutte (1987a,b), Manhardt (1972), Carpenter and Strawser (1970), Director and Doctors (1973), Morgan, Bremser and Chou (1980), and Lathan, et al (1987). The subjects were asked to rank the job attributes in order of perceived importance using a five-point Likert scale. A rating of 5 corresponded to "extremely important"; a rating of 1 , "not important."

Chi-squared analysis was used to test the relationships between the 35 job attributes and individual characteristics of the subjects, such as gender, age, career aspirations, stage in the job interviewing process, previous accounting experience, and previous non-accounting office experience. Chi-squared analysis also was used to investigate the relationships between career aspirations and gender, marital status, and grade point average. 
TABLE 1

Selected Subject Demographics $(n=172)$.

\section{Category}

Number of Percentage

Gender: Male Subjects of Sample

Age:

Female

86
86

$50.0 \%$

$50.0 \%$

Under 25
25 or over

120

$69.8 \%$

Year in School:

Junior

Senior

Graduate

Cumulative GPA:

Under 2.00

2.00-2.49

2.50-2.99

3.00-3.49

3.50-4.00

52

$30.2 \%$

$31.4 \%$

$64.0 \%$

110

$4.6 \%$

Marital Status:

Married $\quad 35$

Not married $\quad 137$

Children:

Yes 28

No $\quad 144$

International Student:

Yes 7

No 165

Number of On-Campus Interviews:

None 99

1-3

4-6

7-9

10-14

15 or more

Number of Office Visits: None $\quad 130 \quad 75.6 \%$

$\begin{array}{lll}1-3 & 31 & 18.0 \%\end{array}$

4-5

More than

6

$3.5 \%$

$52.9 \%$

Off-Campus Interviews:

Yes 47

$27.3 \%$

No 12

$371.5 \%$

Number of Job Offers:

None $\quad 118 \quad 68.6 \%$

$\begin{array}{lll}1-3 & 51 & 29.7 \%\end{array}$

$\begin{array}{lll}4-5 & 1 & 0.6 \%\end{array}$

More than $5 \quad 2 \quad 1.2 \%$

Previous Full-Time Accounting Experience:

Yes $\quad 34 \quad 19.7 \%$

No $138 \quad 80.2 \%$

Previous Non-Accounting Office Experience:

$\begin{array}{lll}\text { Yes } & 58 & 33.7 \%\end{array}$

$\begin{array}{lll}\text { No } & 113 & 65.7 \%\end{array}$

Top Career Aspiration: Public accounting $74 \quad 43.0 \%$ Internal auditing $17 \quad 9.9 \%$ Govt/nonprofit $\quad 17 \quad 9.9 \%$ Industrial acct. $57 \quad 33.1 \%$ Graduate/law school $6 \quad 3.5 \%$

Other

5

$2.9 \%$

\section{Results and Discussion}

The mean importance ratings for the 35 job attributes are listed in rank order in Table 2. Respondents listed job security as the job attribute considered most important in selecting their first job, followed in order by: challenging and interesting work, advancement potential, employerpaid health insurance, and personalities of supervisors and co-workers. The five factors with the lowest overall rankings were: after-hours social activities, size of organization, location of office within city, on-premise recreational facilities, and on-premise day care facilities.

Starting salary tied for 22nd place on the list of 35 factors, behind most employer-paid fringe benefits. This ranking is surprisingly low even if one considers the findings of previous studies by Carpenter and Strawser (1970), Johnson and Simonson (1970), Director and Doctors (1973), and Catalanello, Wegener, and Zikmund (1978), all of which found that accounting students value other job attributes more highly than salary. Expected future salary tied for ninth on the list, indicating that while students are willing to wait for higher salaries, they are not willing to forego them altogether.

The high rankings assigned to job security, challenging and interesting work, and advancement potential all are consistent with the findings of Carpenter and Strawser (1970), Johnson and Simonson (1970), and Director and Doctors (1973). The rankings of region or city in which the firm is located, which placed 13th on the list, and prestige or reputation of firm, which placed 21 st, are lower than might have been predicted from the results of the Johnson and Simonson (1970) and Director and Doctors (1973) studies. Particularly surprising are the high rankings of fringe benefits. In the Director and Doctors (1973) study, pensions ranked last of the eight job selection criteria studied.

\section{Gender Differences}

Gender differences at the .05 level of probability were observed in four of the attributes: office support, employer-paid pregnancy leave, after-hours social activities, and on-premise day care facilities. Of these, both employerpaid pregnancy leave and on-premise day care facilities also reflected gender differences at the .005 level of probability. Analysis of the data suggests that men are more concerned than women are about office support and afterhours social activities, while women are much more likely to rate employer-paid pregnancy leave and on-premise day care facilities as important job attributes.

The gender differences observed in the present study are consistent with the finding of Lathan, et al (1987) that women are more likely than men to rank fringe benefits highly as a job selection factor. However, the present study suggests that such differences exist only for fringe benefits which affect women uniquely, specifically, bene- 
fits relating to childbearing or child care. Significant gender differences were not observed for the six other fringe benefits listed in the questionnaire. The present study provides no evidence to support the findings of the Lathan study that women place greater importance than men do in continuing professional development, starting salary, travel responsibilities, and location of firm. The present study also provides no support for the finding of Reed and Kratchman (1989) that men are more interested than women are in jobs that allow them to exercise leadership or the finding of Centers and Bugenthal (1966) that women are more likely than are men to value good coworkers. The conclusion reached by Manhardt (1972) that men are more concerned than are women with job attributes relating to long-term career advancement is not reflected in the results of the present study. However, the present data do support Manhardt's assertion that childbearing responsibilities continue to have a significant impact on women's career choices.

\section{Age Differences}

Age differences at the .05 level of significance were observed in three of the attributes: expected future salary, starting salary, and employer-paid pregnancy leave. The data suggest that students 25 years old or older place greater importance on starting salary than do students under 25 , while younger students are more likely to consider expected future salary when choosing a job. Such findings are not surprising, since older students are more likely to have families and thus have greater immedi-

ate financial needs, while younger students, without such needs, have the option of taking a job which offers a relatively low starting salary but which may open the door to higher-paying positions in the future. The data also suggest that students 25 or older are more interested than are younger students in employer-paid pregnancy leave, which, again, is not surprising given the family responsibilities facing many older students. The present study does not support Schmutte's (1987a,b) findings that older students are less concerned about prestige or reputation of the firm and more concerned about personalities of supervisors and co-workers.

\section{Work Experience Differences}

The data show that significant differences relating to previous accounting experience exist at the .05 probability level for only one job attribute: recommendations of others. Students with previous accounting experience appear to be more inclined to rely on the opinions of others in
TABLE 2

Rank Order of Job Selection Preferences.

\begin{tabular}{lcc} 
Job Attribute & $\begin{array}{c}\text { Overall } \\
\text { Mean }\end{array}$ & $\begin{array}{c}\text { Standard } \\
\text { Deviation }\end{array}$ \\
\hline
\end{tabular}

4. Employer -paid health insurance $\quad 4.23 \quad 0.80$

5. Personalities of supervisors and co-workers $\quad 4.19 \quad 0.71$

6. Employer-paid retirement plan $\quad 4.17 \quad 0.86$

7. Growth potential of company $\quad 3.98 \quad 0.83$

8. Company policies and administration $\quad 3.95 \quad 0.81$

9. Expected future salary $\quad 3.92 \quad 0.75$

10. Continuing professional development $\quad 3.92 \quad 0.89$

11. Diversity of work assignments $3.92 \quad 0.84$

12. Employer-paid disability insurance $\quad 3.88 \quad 0.94$

3. Region or city in which firm is located $\quad 3.84 \quad 1.06$

15. Employer-paid life insurance $\quad 3.83 \quad 0.98$

7. Opportunity to exercise leadership

18. Opportunity to work as part of team $\quad 3.59 \quad 0.96$

19. Flexible work schedule $\quad 3.43 \quad 1.07$

20. Opportunity to be creative $\quad 3.41 \quad 0.93$

21. Prestige or reputation of firm $\quad 3.38 \quad 0.93$

22. Starting salary $\quad 3.31 \quad 0.70$

$3.31-0.85$

$3.31 \quad 0.89$

. Recognition and visibility of work $\quad 3.28 \quad 0.85$

28. Frequency of performance evaluations

$3.26 \quad 0.93$

$3.24 \quad 1.07$

$3.17 \quad 0.95$

$2.98 \quad 0.86$

$2.98 \quad 1.54$

$2.72 \quad 1.11$

$2.70 \quad 0.97$

$2.65 \quad 1.07$

$2.53 \quad 1.09$

$2.34 \quad 1.24$ choosing a job than students without similar experience. This difference may reflect the fact that students with previous accounting experience have acquired more job contacts and are better able to seek out and take advantage of career advice than students who have few contacts.

When the data are analyzed according to previous non-accounting office experience, on-premise recreational facilities is the only job attribute which reflects a significant difference at the .05 level. The data suggest that students with previous non-accounting experience are less likely than those who have such experience to consider recreational facilities when selecting a job. This difference may suggest that while a weight room or indoor basketball court may be enticing to a first-time job applicant coming from a college or university which offers such facilities, the worker is likely to discover as he or she gains experience either that the benefits of recreational facilities are insignificant compared to other job factors or that membership in a private health club is an acceptable alternative. 


\section{Career Aspiration Differences}

The respondents were asked to rank their top three career aspirations from a list which included: public accounting, internal auditing, governmental/nonprofit accounting, industrial accounting, graduate/law school, and "other." Forty-three percent ranked public accounting as their number one choice, and 33 percent ranked industrial accounting as number one (see Table 1).

Application of chi-squared tests to the data indicates that, at the .05 level of significance, differences exist for four of the job attributes listed: personalities of supervisors and co-workers, recommendations of others, travel responsibilities, and employer-paid pregnancy leave. Subjects ranking public accounting as their top choice considered personalities of supervisors and co-workers and recommendations of others to be more important than other subjects did. These findings may be a reflection of the pressure-filled environment of many public accounting firms, where competition for advancement is keen and turnover is high. Perhaps public accounting aspirants, having heard frightening stories about the public accounting environment, are more wary than other students of potential on-the-job personality clashes and, as a precaution, are more likely to seek the opinions of other students and accounting faculty members before selecting their first jobs.

Subjects hoping to enter governmental or not-for-profit accounting, in contrast, attached more importance to travel responsibilities and employer-paid pregnancy leave. These findings may be explained by the observation of Bellante and Link (1981) that public-sector jobs tend to attract people who are risk averse. Students with family responsibilities tend to be more risk averse and concerned about job security, since they must rely on a steady source of income to meet family expenses. These people are likely to be attracted to jobs with limited travel requirements and generous pregnancy-leave policies.

\section{Other Differences}

The data were also broken down by the number of job interviews, office visits, and job offers each student received. The purpose of this analysis was to explore the effects of the job interviewing process on students' perceptions of the relative importance of the various job attributes. The results suggest that the interviewing process has little impact on students' job selection preferences. Of the 35 job attributes studies, two attributes, opportunity to help others and size of organization, showed a significant difference at the .05 significance level when the data were broken down by number of job interviews. The data appear to suggest that both attributes are positively related to number of interviews. When the data were analyzed by number of office visits, advancement potential was the only attribute which showed a sig- nificant difference at the .05 level. The importance attached to advancement potential appeared to increase as the number of job interviews increased. Size of organization was the only attribute which revealed a significant difference when the data were analyzed by number of job offers. Again, the data suggest a positive relationship between the variables. Conclusions concerning the above relationships are difficult to make, since the job attributes showing significant differences were not consistent during the three phases of the interviewing process.

The findings of the present study generally are consistent with the conclusions of Schmutte $(1987 \mathrm{a}, \mathrm{b})$, who found that on-campus interviews did little to shape the attitudes of students toward public accounting firms. The present study also supports Schmutte's specific finding that students who had gone through the interviewing process placed greater importance on the size of the organization's professional staff than those who had not. However, the present study provides no evidence to support Schmutte's finding that the perceived importance of a "relaxed office atmosphere" increased as students went through the interviewing process; the job attribute in the present study most closely related to office atmosphere, personalities of supervisors and co-workers, showed no significant difference at the .05 level. Conversely, the finding of the present study that a relationship exists between the relative importance assigned to advancement potential and the number of job interviews in which the subject has participated is not supported by the Schmutte study, which found that students ranked advancement opportunity as the most important job attribute both before and after the interviewing process.

The present study also explored the relationship between grade point average and previous work experience and the students' success during the various stages of the interviewing process. The data showed a significant relationship between GPA and office visits at the .005 level of significance. However, no relationship existed between GPA and either on-campus interviews, off-campus interviews, or job offers at the .05 significance level. The fact that GPA appeared to be correlated to office visits but not to job offers, which normally are made soon after the office visit, may at first seem surprising. However, Pasewark, Strawser, and Wilkerson (1988) point out that the factors that lead to the selection of a student for an office visit are not always the same factors that influence the decision to extend an offer to the student. Although a strong academic record may be enough to get a student an invitation for an office visit, the personal qualities the student exhibits-personality, appearance, and ability to "fit in" with the people in the organization-are often the factors that lead to a job offer.

Previous full-time experience in the accounting field apparently is valued highly by employers when making hiring decisions. At the .005 level of significance, a positive relationship existed between previous accounting 
experience and number of job offers received. No significant relationship existed between previous accounting experience and either number of on-campus interviews or number of office visits, even at the .05 level of significance. Previous full-time experience outside the accounting field apparently makes little difference to employers at any stage of the interviewing process. At the .05 level of significance, no relationship was found between previous non-accounting experience and either number of oncampus interviews, number of office visits, or number of job offers.

\section{Suggestions for Further Research}

Other possibilities exist for expanding the scope of the present research. Future researchers may wish to consider the impact of students' perceptions of campus recruiters on the job selection preferences of students. Perhaps students who have negative impressions of the recruiters whom they have met come away from the interviewing process with job perceptions significantly different from those of students who have positive impressions of the recruiters. Also, research might be conducted to determine whether job selection preferences actually influence job choices. Future researchers might interview the same students before and after they have selected their first jobs to determine whether the students rationally took into account their perceptions of job attributes, or whether the students reacted impulsively to last-minute sales pitches by prospective employers. Such findings could greatly benefit departmental administrators, academic advisors, recruiters, and college placement officials seeking to understand the factors accounting students consider in selecting their first jobs.

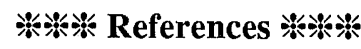

1. Belkaoui, A. (1986, Fall). "The Accounting Students' Need for Achievement and Career Aspirations: An Experiment." Issues in Accounting Education, 1 (2), 197-206.

2. Bellante, D., \& Lind, A. (1981, April). "Are Public Sector Workers More Risk Averse Than Private Sector Workers?" Industrial and Labor Relations Review, 34(3), 408-412.

3. Carpenter, C.G., \& Strawser, R.H. (1970, June). "Job Selection Preferences of Accounting Students." The Journal of Accountancy, 84-86.

4. Catalanello, R.F., Wegener, S.M., \& Zikmund, W.G. (1978, Fall). "A Career Choice Experiment." College Student Journal, 12, 310319.

5. Centers, R., \& Bugenthal, D.E. (1966, June). "Intrinsic and Extrinsic Job Motivations among Different Segments of the Working Population." Journal of Applied Psychology, 193-197.

6. Dinius, S.H., \& Rogow, R.B. (1988). "Application of the Delphi Method in Identifying Characteristics Big Eight Firms Seek in Entry-Level Accountants." Journal of Accounting Education, 83101.

7. Director, S.M., \& Doctors, S.I. (1973, Spring). "Do Business School Students Really Care About Social Responsibility?" Business and Society Review/Innovation, 91-95.
8. Hassell, J.M., \& Hennessey, H.W. (1989). "An Examination of Factors Important in the CPA Recruiting Process." Journal of Accounting Education, 7, 217-231.

9. Johnson, A.C., \& Simonson, J. (1970, Fall). "The College Graduate and His First Job." Management of Personnel Quarterly, 18-23.

10. Kochanek, R.F., \& Norgaard, C.T. (1985a, May). "Student Perceptions of Alternative Accounting Careers-Part I." The CPA Journal, 36-43.

11. (1985b, June). "Student Perceptions of Alternative Accounting Careers-Part II." The CPA Journal, 26-32.

12. Lathan, M.H., Ostrowski, B.A., Pavlock, E.J., Scott, R.A.(1987, January). "Recruiting Entry Level Staff: Gender Differences." The CPA Journal, 30-42.

13. Manhardt, P.J. (1972)."Job Orientation of Male and Female College Graduates in Business." Personnel Psychology, 25, 361-368.

14. Morgan, R.G., Bremser, W.G., \& Chou, C. (1980, October). "Are Expectations Realistic?: Job Expectations of Entrants into the Accounting Profession." The Woman CPA, 13-17.

15. Pasewark, W.R., Strawser, J.R., \& Wilkerson, J.E., Jr. (1988, Fall). "Empirical Evidence on the Association Between Characteristics of Graduating Accounting Students and Recruiting Decisions of Accounting Employers," Issues in Accounting Education, 3 (2), 388-401.

16. Powell, G.N. (1984). "Effects of Job Attributes and Recruiting Practices on Applicant Decisions: A Comparison." Personnel Psychology, 37, 721-732.

17. Reed, S.A., \& Kratchman, S.H. (1987, Autumn). "Job Satisfaction: Differences Throughout the Accounting Profession." The Ohio CPA Journal, 33-47.

18. (1989). "A Longitudinal and Cross-Sectional Study of Students' Perceptions of the Importance of Job Attributes." Journal of Accounting Education, 7, 172-193.

19. Schmutte, J. (1987a, Spring). "The Importance of On-Campus Interviews to Local and Regional Accounting Firms." The Ohio CPA Journal, 23-25.

20. (1987b, Fall). "The Socialization Effect of the Phase of the Placement Process." Issues in Accounting Education, 2 (2), 292-312.

21. Shivaswamy, M.K., \& Hanks, G.F. (1986, December). "Career Preferences of Accounting Students: Are Occupational Choices Restricted?" Journal of Education for Business, 119-122.

22. Sterner, J.A., Yunker, P.J., \& Costigan, M. (1984, March). "How Accounting Students View Potential Employment Conditions." The National Public Accountant, 36-38.

23. Yunker, P.J., Sterner, J.A., \& Costigan, M. (1986, Spring). "Employment in Accounting: A Comparison of Recruiter Perceptions with Student Expectations." Journal of Accounting Education, 95-112. 